\title{
REVIEW
}

\section{Assessment of volume responsiveness during mechanical ventilation: recent advances}

\author{
Xavier Monnet*, Jean-Louis Teboul \\ This article is one of ten reviews selected from the Annual Update in Intensive Care and Emergency Medicine 2013 and co-published as a series \\ in Critical Care. Other articles in the series can be found online at http://ccforum.com/series/annualupdate2013. Further information about the \\ Annual Update in Intensive Care and Emergency Medicine is available from http://www.springer.com/series/8901.
}

\begin{abstract}
Introduction
Predicting which patients with acute circulatory failure will respond to fluid by a significant increase in cardiac output is a daily challenge, in particular in the setting of the intensive care unit (ICU). This challenge has become even more crucial because evidence is growing that administering excessive amounts of fluid is a risk factor in critically ill patients, in particular in patients with lung injury. However, some tests and indices allow prediction of fluid responsiveness before intravenous fluids are infused. In patients receiving mechanical ventilation, the arterial pulse pressure variation (PPV) has been used for many years. More recently, other tests, which may overcome some limitations of PPV, have been developed. In addition, recent studies have emphasized how the hemodynamic effects of volume expansion should be assessed once fluid has been administered.
\end{abstract}

\section{The concept of predicting fluid responsiveness}

Volume expansion is the first-line treatment in the majority of cases of acute circulatory failure. Fluid is administered with the expectation that it will increase cardiac preload and cardiac output to a significant extent. Nevertheless, this can occur only if cardiac output is dependent upon cardiac preload, i. e., if both ventricles operate on the ascending limb of the cardiac function curve [1] (Fig. 1). If this is not the case, volume expansion may only exert adverse effects without having any hemodynamic benefit. An important point is that excessive fluid administration has been demonstrated to increase mortality during septic shock $[2,3]$ and to prolong mechanical ventilation during acute respiratory distress syndrome (ARDS) [4]. In the same context, the

*Correspondence: xavier.monnet@bct.aphp.f

Hôpitaux universitaires Paris-Sud, Hôpital de Bicêtre, service de réanimation médicale, Univ Paris-Sud, EA4533, 78, rue du Général Leclerc, Le Kremlin-Bicêtre, F-94270 France amount of extravascular lung water (EVLW), i. e., the volume of lung edema, has been demonstrated to be related to mortality in critically ill patients [5] and, more recently, to be an independent prognostic factor during ARDS [6]. Thus, fluid responsiveness should be detected before deciding to administer volume expansion, especially in patients in whom fluid overload should be particularly avoided, i. e., patients with septic shock and/ or ARDS.

For this purpose, 'static' markers of cardiac preload have been used for many years. Nevertheless, a very large number of studies clearly demonstrate that neither pressure nor volume markers of preload can predict fluid responsiveness $[7,8]$. This finding is mainly because a given value of preload can correspond to either a large or a negligible response of cardiac output to fluid administration, depending upon the slope of the Frank-Starling curve, which cannot be a priori determined in a given patient (Figure 1). This is the reason why a 'dynamic approach' has been developed for assessing volume responsiveness [9]. The concept is to assess preloaddependency by observing the effects on cardiac output of changes in cardiac preload induced by various tests.

\section{Monitoring respiratory variations in stroke volume: a large base of evidence \\ Pulse pressure variation}

The first application of this 'dynamic' concept consisted of quantifying the variations in stroke volume induced by positive-pressure ventilation [10]. As a result of heartlung interactions, each mechanical insufflation decreases venous return and, if the right ventricle is preloaddependent, reduces the right ventricular (RV) outflow. Increase in RV afterload induced by increased lung volume contributes to this reduction in RV outflow. In turn, this results in a decrease in left ventricular (LV) preload, which occurs after a delay of a few cardiac cycles, required for the blood to transit through the 


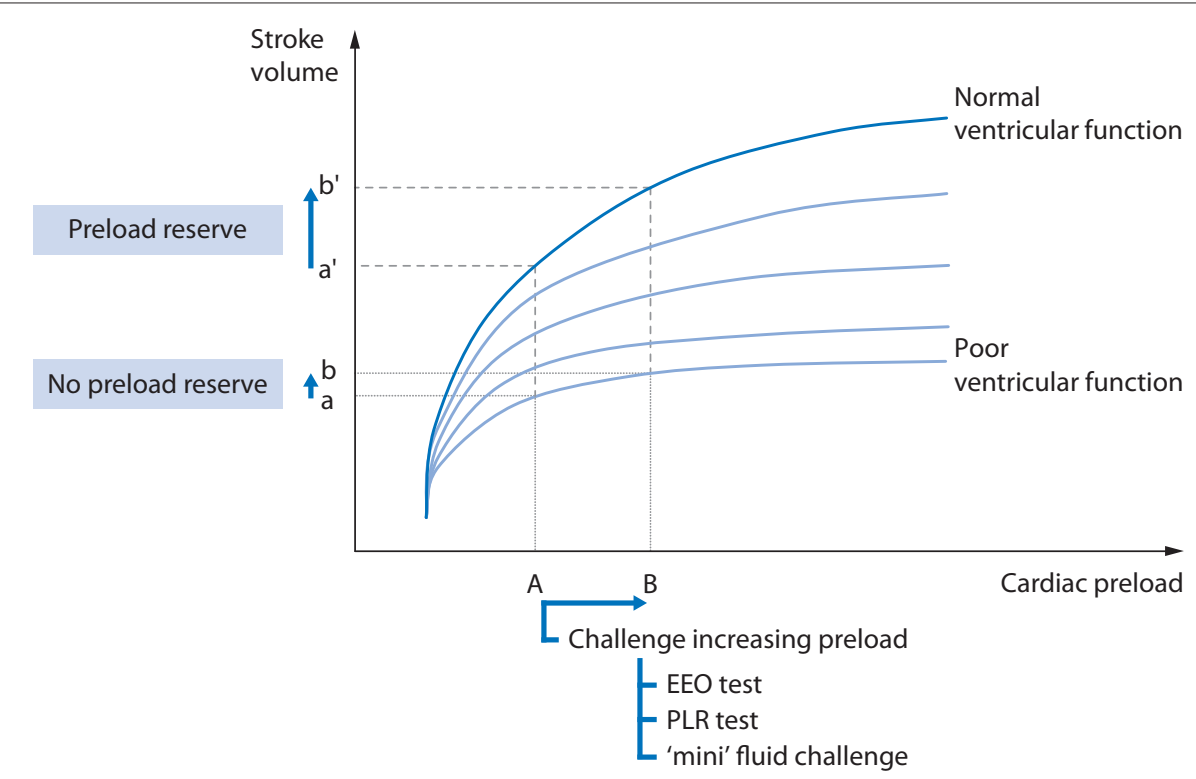

Figure 1. Functional hemodynamic monitoring for assessing the Frank-Starling relationship in patients with spontaneous breathing activity and/or cardiac arrhythmias and/or low tidal volume and/or low lung compliance. The same increase in cardiac preload (from $A$ to $B$ ) induced by volume expansion can result in a significant (from $a^{\prime}$ to $b^{\prime}$ ) or to a negligible (from $a$ to $b$ ) increase in stroke volume depending upon the shape of the curve. A static value of preload $(A)$ does not predict to which extent stroke volume will respond to increased cardiac preload induced by fluid administration. Functional hemodynamic monitoring consists of observing the resulting effects of a preload variation, as can be induced by an end-expiratory occlusion test (EEO), a passive leg raising test (PLR) or by a 'mini' fluid challenge.

lungs. In the case of conventional ventilation, this effect should occur at expiration. If the left ventricle is also preload-dependent, the LV stroke volume transiently decreases. As a result, a cyclic variation in stroke volume under mechanical ventilation indicates the existence of preload-dependency of both ventricles [10].

The arterial pulse pressure (systolic minus diastolic arterial pressure) as a surrogate of stroke volume has been proposed to predict fluid responsiveness through its respiratory variation [10]. A number of studies conducted in various clinical settings have repeatedly demonstrated that PPV actually predicts fluid responsiveness [11]. Among the different indicators of fluid responsiveness, PPV is supported by the highest level of evidence. Importantly, PPV is calculated automatically and displayed in real-time by the most recent bedside hemodynamic monitors.

\section{Other surrogates of stroke volume}

Almost all indices that provide a beat-to-beat estimation of stroke volume have been investigated for their ability to test fluid responsiveness by their respiratory variation: Aortic blood flow measured by esophageal Doppler [12]; subaortic peak velocity measured by echocardiography [13]; stroke volume estimated from pulse contour analysis [14]. Some recent studies have investigated non-invasive estimations of stroke volume, such as the non-invasive arterial pulse pressure estimated by the volume-clamp method $[15,16]$ or the amplitude of the plethysmographic waveform [17]. All these non-invasive methods still require confirmatory studies, but they may be of great interest for the perioperative management of low-risk surgical patients, when there is no need for an invasive monitoring device.

Finally, analysis of respiratory variations of the diameter of the inferior vena cava (using transthoracic echocardiography) [18] or of the superior vena cava (using transesophageal echocardiography) [19] can also be used to assess fluid responsiveness in mechanically ventilated patients.

\section{Limitations of the respiratory variation in stroke volume for predicting fluid responsiveness}

The use of respiratory variation of stroke volume or surrogates to predict fluid responsiveness has some limitations that are now clearly identified. The first and most important limitation is the presence of some spontaneous breathing activity [20]. When a patient has some breathing efforts under mechanical ventilation and even more when the patient is not intubated - the variation in intrathoracic pressure is not regular, neither in rate nor in amplitude, such that the variation in stroke volume cannot relate to preload-dependency [21-23]. Thus, using the respiratory variation of stroke volume to test the preload sensitivity is valid only in cases of coma or deep sedation during mechanical ventilation, a condition that has become less frequent in the ICU. 
A second limitation of using the respiratory variation in stroke volume is the presence of cardiac arrhythmias as in these cases, the variation in stroke volume is obviously more related to the irregularity of diastole than to heart-lung interactions.

A third limitation refers to conditions in which the variations in intravascular pressure induced by mechanical ventilation are of small amplitude. In the case of low tidal volume, the small variations in intrathoracic pressure may not be sufficient to trigger significant preload variations, even in cases of preload responsiveness. Some studies have actually shown that PPV loses its predictive value in the case of low tidal volume $[24,25]$. The changes in intravascular pressure induced by mechanical ventilation may also be reduced if the transmission of changes in alveolar pressure to the pressure of the intrathoracic structures is attenuated, e. g., in the case of low lung compliance. A recent clinical study demonstrated that if the compliance of the respiratory system is less than $30 \mathrm{ml} / \mathrm{cm} \mathrm{H}_{2} \mathrm{O}$, the value of PPV for predicting fluid responsiveness is dramatically reduced, independently of tidal volume [26].

A fourth limitation is the use of high frequency ventilation. If the ratio of heart rate to respiratory rate is low, e. g., if the respiratory rate is elevated, the number of cardiac cycles per respiratory cycle may be too low to allow respiratory stroke volume variation (SVV) to occur [27]; nevertheless, this applies to respiratory rates as high as 40 breaths/min [27].

A fifth limitation is the presence of increased abdominal pressure [28,29]. In such cases, a higher PPV cut-off value must be considered for the prediction of fluid responsiveness [28]. Finally, open-chest surgery is another situation where the ventilation-induced variation of hemodynamic signals loses its predictive value for fluid responsiveness [30].

Except for open-chest conditions, the limitations of PPV and surrogates as predictors of fluid responsiveness mainly concern the intensive care setting and not the operating room where these heart-lung interaction indices are fully relevant. During recent years, alternative methods have been developed for predicting fluid responsiveness in critically ill patients (Figure 2).

\section{Alternatives to the respiratory variation of hemodynamic signals: recent advances The end-expiratory occlusion test}

This test is another method that takes advantage of heartlung interactions to predict fluid responsiveness in ventilated patients. During mechanical ventilation, each insufflation increases the intrathoracic pressure and impedes venous return. Thus, interrupting the respiratory cycle at end-expiration inhibits the cyclic impediment in venous return. The resulting increase in cardiac preload may thus help to test preload responsiveness (Fig. 1). Indeed, it was demonstrated that if a 15-second endexpiratory occlusion test increased the arterial pulse pressure or the pulse contour-derived cardiac output by more than $5 \%$, the response of cardiac output to a $500 \mathrm{ml}$ saline infusion could be predicted with good sensitivity and specificity [31]. Noticeably, all patients of the latter study were arrhythmic or had mild spontaneous breathing activity. These initial results were recently confirmed [26].

Beyond its simplicity, the main advantage of the endexpiratory occlusion test is that it exerts its hemodynamic effects over several cardiac cycles and thus remains valuable in case of cardiac arrhythmias [31]. Also, the end-expiratory occlusion test can be used in patients with spontaneous breathing activity, unless marked triggering activity interrupts the test. Another limitation is that the effects of the end-expiratory occlusion test, which must be observed over $15 \mathrm{~s}$, are much easier to observe on a continuous display of cardiac output than on the arterial pulse pressure because the value of the latter is not continuously calculated and displayed by bedside monitors.

\section{The 'mini' fluid challenge}

Obviously, the easiest way to test preload responsiveness is to administer fluid and to observe the resulting effect on cardiac output. Nevertheless, the disadvantage of the 'classical' fluid challenge is that it consists of administration of $300-500 \mathrm{ml}$ of fluid [32]. Because it is not reversible, such a fluid challenge may contribute to fluid overload, especially when it is repeated several times a day [33].

In this regard, a new method has been proposed for performing a fluid challenge [34]. It consists of administering $100 \mathrm{ml}$ of colloid over $1 \mathrm{~min}$ and observe the effects of this 'mini' fluid challenge on stroke volume, as measured by the subaortic velocity time index using transthoracic echocardiography (Figure 1). In a clinical study, an increase in the velocity time index of more than $10 \%$ predicted fluid responsiveness with a sensitivity of $95 \%$ and a specificity of $78 \%$ [34].

The first advantage of this test over the classical fluid challenge is obviously that such a small volume of fluid is unlikely to induce fluid overload [33], even if repeated several times a day. Another advantage is that it is easy to perform and that it can be assessed in a non-invasive way [34]. Nevertheless, a strong limitation is that, even in cases of preload-dependency, such a small volume infusion will unavoidably induce only small changes in cardiac output. This test, therefore, requires a very precise technique for measuring cardiac output. Whether non-invasive techniques, such as echocardiography, are precise enough for this purpose is still uncertain. Finally, 


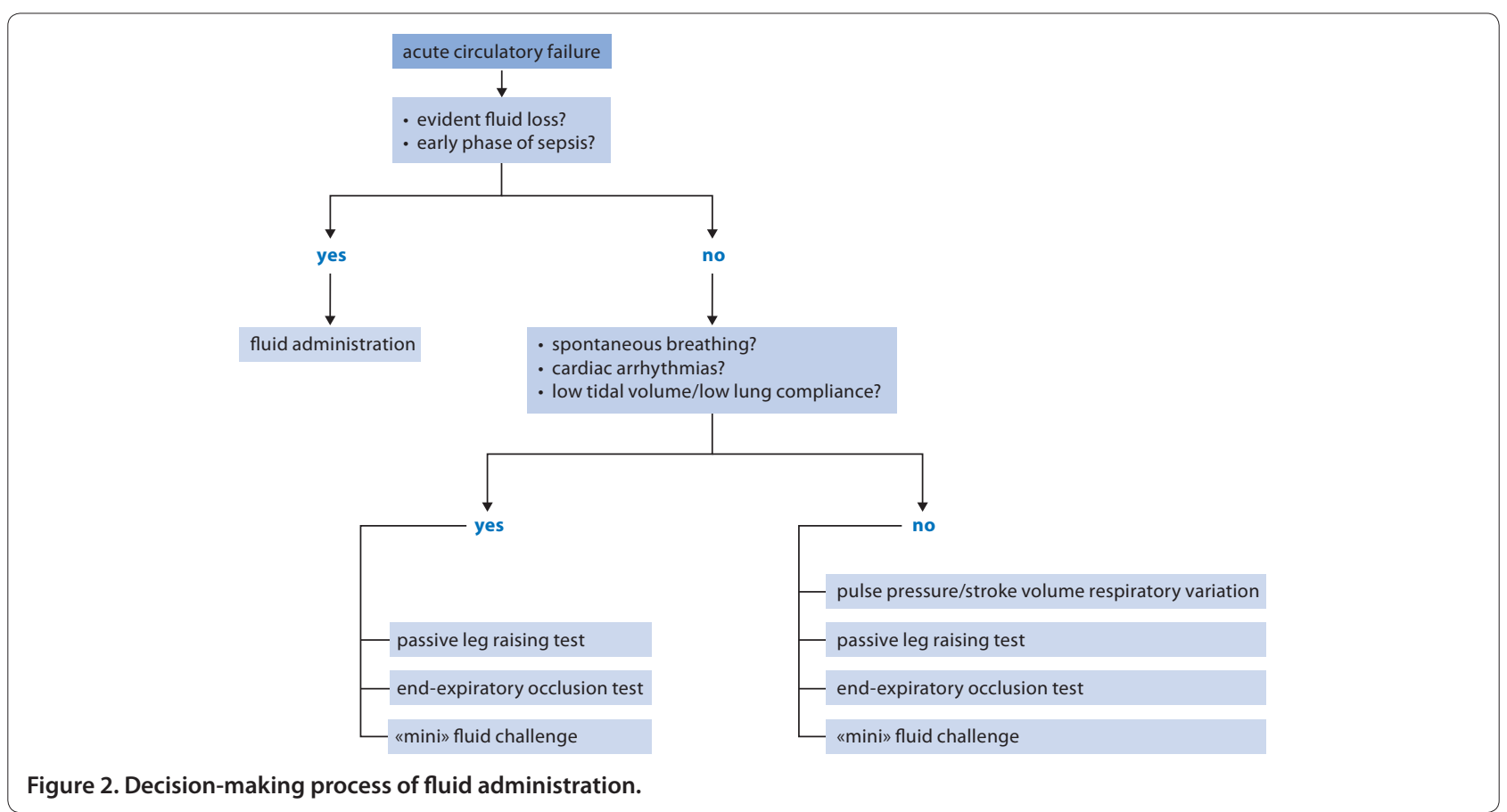

this method cannot be used in the presence of cardiac arrhythmias. In the study by Muller et al., one fourth of patients were excluded because of this limitation [34].

\section{The passive leg-raising test}

In a lying subject, raising the legs from the horizontal position passively transfers a significant volume of blood from the lower part of the body toward the cardiac chambers: Passive leg-raising (PLR) partially empties the venous reservoir and converts a part of the unstressed blood volume to stressed volume. In this connection, PLR increases right [35-37] and left [22,35] cardiac preload. Eventually, the increase in left cardiac preload results in an increase in cardiac output depending upon the degree of preload reserve of the left ventricle. The increase in cardiac preload induced by PLR totally reverses once the legs are returned back to the supine position $[22,35,36]$. In summary, PLR acts like a reversible and short-lived 'self' volume challenge [38] (Fig. 1). As a clinical application of this simple physiological concept, several studies reported that the increase in cardiac output induced by the PLR test enables prediction of fluid responsiveness; many of these studies were included in a meta-analysis [39]. These findings have contributed to establish PLR as a reliable and easy way to predict fluid responsiveness at the bedside [40]. Interestingly, since the test exerts its effects over several cardiac and respiratory cycles, it remains a good predictor of fluid responsiveness in patients with spontaneous breathing activity (even non-intubated) or cardiac arrhythmias [22,31].
The postural change used for performing the PLR test is important [38]. If PLR is started from the $45^{\circ}$ semirecumbent position, the induced increase in central venous pressure is larger than if started from the supine position [36]. In fact, starting PLR from the semirecumbent position mobilizes blood coming not only from the inferior limbs but also from the large splanchnic compartment. As a consequence, starting PLR from the semi-recumbent posture is more sensitive than starting from the horizontal posture to detect fluid responsiveness [36], so that this method should be considered as a standard.

Another important point concerns the method that can be used for measuring the changes in cardiac output during PLR [38]. A real-time measurement able to track hemodynamic changes in the time frame of PLR effects, i. e., 30-90 s, must be used. Indeed, the increase in cardiac output during PLR is not sustained when the leg elevation is prolonged. This aspect is particularly true in septic patients in whom capillary leak may account for an attenuation of the PLR effects after one minute, as already described [22]. This is why clinical studies that have tested the value of PLR to predict volume responsiveness used real-time hemodynamic measurements, such as aortic blood flow measured by esophageal Doppler [22,41], pulse contour analysis-derived cardiac output $[16,26,42]$, cardiac output measured by bioreactance $[43,44]$ or endotracheal bioimpedance cardiography [45], subaortic blood velocity measured by echocardiography [46-48], ascending aortic velocity measured by suprasternal 
Doppler [49] and, more recently, end-tidal carbon dioxide [50,51].

Beyond its reliability and ease of use, the PLR test has some limitations [38]. First, its effects cannot be assessed by observing the arterial pressure. PLR-induced changes in arterial pulse pressure are less accurate than PLRinduced changes in cardiac output or stroke volume, as found by several studies [39]. This finding is explained by the fact that arterial pulse pressure is only a rough surrogate of stroke volume. This means that correct performance of a PLR test requires a device that allows a more direct estimation of cardiac output. Second, the PLR test cannot be used in instances in which mobilizing the patient is not possible or allowed, e. g., in the operating room or in the case of head injury [52].

\section{How to assess the response to volume expansion? Effects of volume expansion on cardiac output}

If the decision is taken to infuse fluid in case of preload reserve, the ensuing question is whether the fluid actually exerts its expected beneficial effects. What is expected from fluid administration is a significant increase in cardiac output. In this regard, it has been recently shown that changes in arterial pressure are relatively imprecise to estimate the effects of fluid infusion on cardiac output [53,54]. In 228 patients who received a standardized saline infusion, fluid-induced changes in arterial pulse pressure were weakly correlated with the simultaneous changes in cardiac output $(r=0.56)$ [54]. Consequently, the changes in pulse pressure induced by volume expansion detected a positive response to fluid (i. e., an increase in cardiac output $\geq 15 \%$ ) with a specificity of $85 \%$ but with a sensitivity of only $65 \%$; in other words, $22 \%$ of cases were false negatives, meaning that in these patients, fluid administration significantly increased cardiac output whereas the arterial pulse pressure did not change to a large extent. Pierrakos et al. confirmed these results in 51 septic shock patients [54], in whom there was no significant correlation between fluid-induced changes in arterial pulse pressure and fluid-induced changes in cardiac output. These results are explained by the fact that arterial pulse pressure is physiologically related to stroke volume but also inversely correlated with arterial compliance [55], which may differ among patients and may change over time in the same patient. Moreover, the proportionality between pulse pressure and stroke volume is physiologically expected at the aortic level, but not at the peripheral arterial level because of the pulse wave amplification phenomenon.

Another important point emphasized by the above cited studies [53,54], is that the fluid-induced changes in cardiac output are not reflected at all by the fluid-induced changes in mean arterial pressure (MAP). Physiologically, the changes in MAP are dissociated from the changes in cardiac output because of the sympathetic modulation of the arterial tone, which tends to maintain MAP constant while cardiac output varies. These results suggest that precise assessment of the effects of volume expansion should not rely on simple blood pressure measurements but should rather be based on direct measurements of cardiac output. This may be particularly important in patients at risk of fluid overload during sepsis and/or ARDS.

\section{Effects of volume expansion on tissue oxygenation}

What is really expected from volume expansion in a patient with acute circulatory failure is not only an increase in cardiac output but also an improvement in tissue oxygenation. This can only occur if oxygen consumption depends on oxygen delivery $\left(\mathrm{DO}_{2}\right)$. However, this is not always the case. In a recent study, we observed that volume expansion administered in patients with acute circulatory failure increased cardiac output $\geq 15 \%$ in $49 \%$ of cases ("volume-responders") [56]. Although $\mathrm{DO}_{2}$ significantly increased in "volumeresponders", a significant increase in oxygen consumption occurred in only $56 \%$ of these patients. When looking at variables that could identify patients who would benefit from volume expansion in terms of oxygen consumption, we found that markers of global tissue hypoxia, such as blood lactate, were more relevant than the central venous oxygen saturation $\left(\mathrm{ScvO}_{2}\right)$. This illustrates the difficulty of using $\mathrm{ScvO}_{2}$ for assessment of fluid therapy [57] because $\mathrm{ScvO}_{2}$ cannot detect preload responsiveness [58] or identify among volume-responders those who will benefit from fluid infusion in terms of tissue oxygenation [56]. Importantly, in our study, $\mathrm{DO}_{2}$ decreased with volume infusion in the "volume-non-responders" (51 \%), owing to development of hemodilution [56]. This latter finding reinforces the message that identifying volume responders before any fluid administration is crucial since volume expansion in patients without preloaddependency can be deleterious not only on lung function but also on peripheral oxygenation.

\section{Conclusion}

There is growing evidence suggesting that overzealous fluid administration is deleterious in critically ill patients, particularly in cases of sepsis and/or lung injury. During recent years, several tests have been developed to detect volume responsiveness before administering fluid. These tests can also serve to detect volume unresponsiveness, which could be helpful at any moment of fluid resuscitation to better assess the benefit/risk ratio of continuing such a strategy [59]. The analysis of respiratory variation in stroke volume has received the largest level of evidence, but cannot be used in cases of spontaneous breathing activity, cardiac arrhythmias, low 
tidal volume or low lung compliance. Some more recently developed tests, such as the end-expiratory occlusion test, the 'mini' fluid challenge and the PLR test can be used as alternative methods, solving the problem of prediction of volume responsiveness in cases of spontaneous breathing activity and/or cardiac arrhythmias. The ideal management of fluid therapy should also include a precise assessment of the effects of volume expansion on cardiac output and tissue oxygen consumption.

\section{Competing interests}

The authors declare that they have no competing interests.

\section{List of abbreviations used}

ARDS: acute respiratory distress syndrome; $\mathrm{DO}_{2}$ : oxygen delivery; $\mathrm{EEO}$ : expiratory occlusion test; EVLW: extravascular lung water; ICU: intensive care unit; LV: left ventricular; MAP: mean arterial pressure; PLR: passive leg-raising; PPV: pulse pressure variation; $\mathrm{RV}$ : right ventricular; $\mathrm{SCVO}_{2}$ : central venous oxygen saturation.

\section{Published: 19 March 2013}

\section{References}

1. Marik PE, Monnet X, Teboul JL: Hemodynamic parameters to guide fluid therapy. Ann Intensive Care 2011, 1:1

2. Vincent JL, Sakr Y, Sprung CL, Ranieri VM, Reinhart K, Gerlach H, Moreno R, Carlet J, Le Gall JR, Payed D, Sepsis Occurrence in Acutely III Patientic Investigators: Sepsis in European intensive care units: results of the SOAP study. Crit Care Med 2006, 34:344-353.

3. Boyd JH, Forbes J, Nakada TA, Walley KR, Russell JA: Fluid resuscitation in septic shock: A positive fluid balance and elevated central venous pressure are associated with increased mortality. Crit Care Med 2011, 39:259-265.

4. Wiedemann HP, Wheeler AP, Bernard GR: Comparison of two fluid-management strategies in acute lung injury. N Engl J Med 2006, 354:2564-2575.

5. Sakka SG, Klein M, Reinhart K, Meier-Hellmann A: Prognostic value of extravascular lung water in critically ill patients. Chest 2002, 122:2080-2086

6. Jozwiak M, Silva S, Persichini R, Anquel N, Osman D, Richard C, Teboul JL, Monnet $X$ : Extra-vascular lung water is an independent prognostic factor in patients with acute respiratory distress syndrome. Crit Care Med, in press.

7. Michard F, Teboul JL: Predicting fluid responsiveness in ICU patients: a critical analysis of the evidence. Chest 2002, 121:2000-2008.

8. Marik PE, Baram M, Vahid B: Does central venous pressure predict fluid responsiveness? A systematic review of the literature and the tale of seven mares. Chest 2008, 134:172-178.

9. Michard F, Teboul JL: Using heart-lung interactions to assess fluid responsiveness during mechanical ventilation. Crit Care 2000, 4:282-289

10. Michard F, Boussat S, Chemla D, Anquel N, Mercat A, Lecarpentier Y, Richard C, Pinsky MR, Teboul JL: Relation between respiratory changes in arterial pulse pressure and fluid responsiveness in septic patients with acute circulatory failure. Am J Respir Crit Care Med 2000, 162:134-138.

11. Marik PE, Cavallazzi R, Vasu T, Hirani A: Dynamic changes in arterial waveform derived variables and fluid responsiveness in mechanically ventilated patients: a systematic review of the literature. Crit Care Med 2009, 37:2642-2647.

12. Monnet X, Rienzo M, Osman D, Anquel N, Richard C, Pinsky MR, Teboul: Esophageal Doppler monitoring predicts fluid responsiveness in critically ill ventilated patients. Intensive Care Med 2005, 31:1195-1201.

13. Feissel M, Michard F, Mangin I, Ruyer O, Faller JP, Teboul JL: Respiratory changes in aortic blood velocity as an indicator of fluid responsiveness in ventilated patients with septic shock. Chest 2001, 119:867-873.

14. Berkenstadt $H$, Margalit $N$, Hadani M, Friedman Z, Segal E, Villa Y, Perel A: Stroke volume variation as a predictor of fluid responsiveness in patients undergoing brain surgery. Anesth Analg 2001, 92:984-989.

15. Biais M, Stecken L, Ottolenghi L, Roullet S, Quinart A, Masson F, Sztark F. The ability of pulse pressure variations obtained with CNAPTM device to predict fluid responsiveness in the operating room. Anesth Analg 2011, 113:523-528.

16. Monnet X, Dres M, Ferre A, Le Teuff G, Jozwiak M, Bleibtreu A, Le Deley MC, Chemlas D, Richard C, Teboul JL: Prediction of fluid responsiveness by a continuous non-invasive assessment of arterial pressure in critically ill patients: comparison with four other dynamic indices. Br J Anaesth 2012, 109:330-338.

17. Sandroni C, Cavallaro F, Marano C, Falcone C, De Santis P, Antonelli M: Accuracy of plethysmographic indices as predictors of fluid responsiveness in mechanically ventilated adults: a systematic review and meta-analysis. Intensive Care Med 2012, 38:1429-1437.

18. Feissel M, Michard F, Faller JP, Teboul JL: The respiratory variation in inferior vena cava diameter as a guide to fluid therapy. Intensive Care Med 2004, 30:1834-1837

19. Vieillard-Baron A, Chergui K, Rabiller A, Peyrouset O, Page B, Beauchet A, Jardin F: Superior vena caval collapsibility as a gauge of volume status in ventilated septic patients. Intensive Care Med 2004, 30:1734-1739.

20. Teboul JL, Monnet X: Prediction of volume responsiveness in critically ill patients with spontaneous breathing activity. Curr Opin Crit Care 2008, 14:334-339.

21. Heenen S, De Backer D, Vincent JL: How can the response to volume expansion in patients with spontaneous respiratory movements be predicted? Crit Care 2006, 10:R102.

22. Monnet X, Rienzo M, Osman D, Anguel N, Richard C, Pinsky MR, Teboul JL: Passive leg raising predicts fluid responsiveness in the critically ill. Crit Care Med 2006, 34:1402-1407.

23. Soubrier S, Saulnier F, Hubert H, Delour P, Lenci H, Ominus T, Nseir S, Durocher $\mathrm{A}:$ Can dynamic indicators help the prediction of fluid responsiveness in spontaneously breathing critically ill patients? Intensive Care Med 2007 33:1117-1124

24. De Backer D, Heenen S, Piagnerelli M, Koch M, Vincent JL: Pulse pressure variations to predict fluid responsiveness: influence of tidal volume. Intensive Care Med 2005, 31:517-523.

25. , Candela D, Zoric L, de La Coussaye JE, Jaber S, Lefrant JY: The influence of the airway driving pressure on pulsed pressure variation as a predictor of fluid responsiveness. Intensive Care Med 2010, 36:496-503

26. Monnet X, Bleibtreu A, Ferré A, Dres M, Gharbi R, Richard C, Teboul JL: Passive leg raising and end-expiratory occlusion tests perform better than pulse pressure variation in patients with low respiratory system compliance. Crit Care Med 2012, 40:152-157.

27. De Backer D, Taccone FS, Holsten R, Ibrahimi F, Vincent JL: Influence of respiratory rate on stroke volume variation in mechanically ventilated patients. Anesthesiology 2009, 110:1092-1097.

28. Jacques D, Bendjelid K, Duperret S, Colling J, Piriou V, Viale JP: Pulse pressure variation and stroke volume variation during increased intra-abdominal pressure: an experimental study. Crit Care 2011, 15:R33.

29. Tavernier B, Robin E: Assessment of fluid responsiveness during increased intra-abdominal pressure: keep the indices, but change the thresholds. Crit Care 2011, 15:134.

30. de Waal EE, Rex S, Kruitwagen CL, Kalkman CJ, Buhre WF: Dynamic preload indicators fail to predict fluid responsiveness in open-chest conditions. Crit Care Med 2009, 37:510-515.

31. Monnet X, Osman D, Ridel C, Lamia B, Richard C, Teboul JL: Predicting volume responsiveness by using the end-expiratory occlusion in mechanically ventilated intensive care unit patients. Crit Care Med 2009, 37:951-956.

32. Vincent JL, Weil MH: Fluid challenge revisited. Crit Care Med 2006, 34:1333-1337.

33. Vincent JL: "Let's give some fluid and see what happens" versus the "minifluid challenge". Anesthesiology 2011, 115:455-456.

34. Muller L, Toumi M, Bousquet PJ, Riu-Poulenc B, Louart G, Candela D, Zoric L, Suehs C, de La Coussave JE, Molinari N, Lefrant JY, AzuRéa Group: An increase in aortic blood flow after an infusion of $100 \mathrm{ml}$ colloid over 1 minute can predict fluid responsiveness: the mini-fluid challenge study. Anesthesiology 2011, 115:541-547.

35. Boulain T, Achard JM, Teboul JL, Richard C, Perrotin D, Ginies G: Changes in $\mathrm{BP}$ induced by passive leg raising predict response to fluid loading in critically ill patients. Chest 2002, 121:1245-1252.

36. Jabot J, Teboul JL, Richard C, Monnet X: Passive leg raising for predicting fluid responsiveness: importance of the postural change. Intensive Care Med 2009, 35:85-90. 
37. Monnet X, Jabot J, Maizel J, Richard C, Teboul JL: Norepinephrine increases cardiac preload and reduces preload dependency assessed by passive leg raising in septic shock patients. Crit Care Med 2011, 39:689-694.

38. Monnet $X$, Teboul JL: Passive leg raising. Intensive Care Med 2008 34:659-663.

39. Cavallaro F, Sandroni C, Marano C, La Torre G, mannocci A, De Waure C, Bello G, Maviglia R, Antonelli M: Diagnostic accuracy of passive leg raising for prediction of fluid responsiveness in adults: systematic review and metaanalysis of clinical studies. Intensive Care Med 2010, 36:1475-1483.

40. Antonelli M, Levy M, Andrews PJ, Chastre J, Hudson LD, Manthous C, Meduri GU, Moreno RP, Putensen C, Stewart T, Torres A: Hemodynamic monitoring in shock and implications for management. International Consensus Conference, Paris, France, 27-28 April 2006. Intensive Care Med 2007, 33:575-590.

41. Lafanechere A, Pene F, Goulenok C, Delahaye A, Mallet V, Choukroun G, Chich JD, Mira JP, Cariou A: Changes in aortic blood flow induced by passive leg raising predict fluid responsiveness in critically ill patients. Crit Care 2006, 10:R132.

42. Biais M, Vidil L, Sarrabay P, Cottenceau V, Revel P, Sztark F: Changes in stroke volume induced by passive leg raising in spontaneously breathing patients: comparison between echocardiography and Vigileo/FloTrac device Crit Care 2009, 13:R195.

43. Benomar B, Ouattara A, Estagnasie P, Brusset A, Squara P: Fluid responsiveness predicted by noninvasive bioreactance-based passive leg raise test. Intensive Care Med 2010, 36:1875-1881.

44. Marik PE, Levitov A, Young A, Andrews L: The use of NICOM (Bioreactance) and Carotid Doppler to determine volume responsiveness and blood flow redistribution following passive leg raising in hemodynamically unstable patients. Chest, in press.

45. Fellahi JL, Fischer MO, Dalbera A, Massetti M, Gerard JL, Hanouz JL: Can endotracheal bioimpedance cardiography assess hemodynamic response to passive leg raising following cardiac surgery? Ann Intensive Care 2012, 2:26.

46. Guinot PG, Zogheib E, Detave M, Moubarak M, Hubert V, Badoux L, Bernard E, Besserve $\mathrm{P}$, Caus T, Dupont $\mathrm{H}$ : Passive leg raising can predict fluid responsiveness in patients placed on venovenous extracorporeal membrane oxygenation. Crit Care 2011, 15:R216.

47. Lamia B, Ochagavia A, Monnet X, Chemla D, Richard C, Teboul JL: Echocardiographic prediction of volume responsiveness in critically ill patients with spontaneously breathing activity. Intensive Care Med 2007 33:1125-1132.

48. Lukito V, Djer MM, Pudjiadi AH, Munasir Z: The role of passive leg raising to predict fluid responsiveness in pediatric intensive care unit patients. Pediatr Crit Care Med 2012, 13:e155-e160.
49. Thiel SW, Kollef MH, Isakow W: Non-invasive stroke volume measurement and passive leg raising predict volume responsiveness in medical ICU patients: an observational cohort study. Crit Care 2009, 13:R111.

50. Monge Garcia MI, Gil Cano A, Gracia Romero M, Monterroso Pintado R, Perez Madueno V Diaz Monrove JC: Non-invasive assessment of fluid responsiveness by changes in partial end-tidal $\mathrm{CO} 2$ pressure during a passive leg-raising maneuver. Ann Intensive Care 2012, 2:9.

51. Monnet X, Bataille A, Magalhaes E, Barrois J, Le Corre M, Gosset C, Guerin L, Richard C, Teboul JL: End-tidal carbon dioxide is better than arterial pressure for predicting volume responsiveness by the passive leg raising test. Intensive Care Med 2012, 39:93-100.

52. De Backer D, Pinsky MR: Can one predict fluid responsiveness in spontaneously breathing patients? Intensive Care Med 2007, 33:1111-1113.

53. Monnet X, Letierce A, Hamzaoui O, Chemla D, Anquel N, Osman D, Richard C, Teboul JL: Arterial pressure allows monitoring the changes in cardiac output induced by volume expansion but not by norepinephrine. Crit Care Med 2011, 39:1394-1399.

54. Pierrakos C, Velissaris D, Scolletta S, Heenen S, De Backer D, Vincent JL: Can changes in arterial pressure be used to detect changes in cardiac index during fluid challenge in patients with septic shock? Intensive Care Med 2012, 38:422-428.

55. Chemla D, Hebert UL, Coirault C, Zamani K, Suard I, Colin P, Lecarpentier Y: Total arterial compliance estimated by stroke volume-to-aortic pulse pressure ratio in humans. Am J Physiol 1998, 274:H500-H505.

56. Monnet $X$, Julien F, Ait-Hamou N: Lactate and veno-arterial carbon dioxide difference/arterial-venous oxygen difference ratio, but not central venous oxygen saturation, predict increase in oxygen consumption in fluid responders. Crit Care Med, in press.

57. Teboul JL, Hamzaoui O, Monnet X: SvO2 to monitor resuscitation of septic patients: let's just understand the basic physiology. Crit Care 2011, 15:1005

58. Velissaris D, Pierrakos C, Scolletta S, De Backer D, Vincent JL: High mixed venous oxygen saturation levels do not exclude fluid responsiveness in critically ill septic patients. Crit Care 2011, 15:R177

59. Teboul JL, Monnet X: Detecting volume responsiveness and unresponsiveness in intensive care unit patients: two different problems, only one solution. Crit Care 2009, 13:175.

doi:10.1186/cc12526

Cite this article as: Monnet $X$, Teboul JL: Assessment of volume responsiveness during mechanical ventilation: recent advances. Critical Care 2013, 17:217 